\title{
Adiposity and cardiovascular risk from adolescence to young adulthood in the Young Hearts Cohort
}

\author{
S. Watson ${ }^{1}$, C. E. Neville ${ }^{1}$, I. S. Young ${ }^{1}$, L. J. Murray ${ }^{1}$, C. A. Boreham ${ }^{2}$, C. Cardwell ${ }^{1}$, \\ J. V. Woodside ${ }^{1}$ and M. C. Mckinley ${ }^{1}$ \\ ${ }^{1}$ Centre for Public Health, Queens University Belfast, Grosvenor Road, Belfast BT12 6BJ, UK and ${ }^{2}$ Institute for Sport and \\ Health, University College Dublin, Dublin, Ireland
}

The association between adiposity and pro-inflammatory and pro-thrombotic risk factors for CVD has been well documented in crosssectional studies ${ }^{(1)}$ in adults. The longitudinal association between change in adiposity and such parameters remains uncertain. The objectives of this study were to firstly examine the relationship between adiposity in adolescence and pro-inflammatory and pro-thrombotic risk factors in young adulthood and then to examine the relationship between change in adiposity during this timeframe and risk factor status in young adulthood.

The analyses are based on data from the Young Hearts (YH) cohort; a longitudinal study of CVD risk factors in a representative sample of young people in Northern Ireland. In total, 476 subjects (245 males and 231 females) were assessed at age 15 and then again in young adulthood (mean age 22.6 years). Indices of fatness at age 15 included BMI and body fat $\%$ that was derived from the sum of four skin folds thickness. Main outcome measures included C-reactive protein (CRP), fibrinogen and white cell count (WCC); these were assessed in a fasting blood sample only at young adulthood. Subjects were categorised as normal weight or overweight/obese using international BMI cut-offs for adolescents ${ }^{(2)}$ and adults ${ }^{(3)}$. CRP values were divided into two groups according to CVD risk; $<3.0 \mathrm{mg} / \mathrm{l}$ lower risk and $>3.0 \mathrm{mg} / \mathrm{l}$ higher risk $^{(4)}$.

As shown in the first table below, significant associations were observed between adolescent adiposity measurements (BMI and body fat $\%$ ) and adult pro-inflammatory and pro-thrombotic risk factors (CRP, fibrinogen and WCC) after adjusting for potential confounders. These associations were attenuated after further adjusting for adult adiposity.

\begin{tabular}{llcccc}
\hline Outcome & \multicolumn{1}{c}{ Predictor } & Estimates $^{1}(95 \% \mathrm{CI})$ & $P$ & Estimates $^{2}(95 \% \mathrm{CI})$ & $P$ \\
\hline CRP & BMI & $0.06(0.02,0.09)$ & 0.00 & $-0.03(-0.08,0.03)$ & 0.35 \\
& Body fat $\%$ & $0.04(0.01,0.06)$ & 0.00 & $0.01(-0.02,0.04)$ & 0.38 \\
Fibrinogen & BMI & $0.07(0.04,0.09)$ & 0.00 & $0.02(-0.02,0.06)$ & 0.25 \\
\multirow{2}{*}{ WCC } & Body fat $\%$ & $0.04(0.02,0.05)$ & 0.00 & $0.03(0.00,0.05)$ & 0.03 \\
& BMI & $0.07(0.00,0.14)$ & 0.05 & $0.01(-0.07,0.09)$ & 0.78 \\
& Body fat $\%$ & $0.05(0.00,0.10)$ & 0.04 & $0.03(-0.02,0.08)$ & 0.24 \\
\hline
\end{tabular}

Data are Beta values and $95 \%$ CI. ${ }^{1}$ Adjusted for sex, social class, pubertal status, history of parental heart attack, smoking, adolescent blood pressure and blood lipoproteins. ${ }^{2}$ Further adjustment for adult BMI and body fat $\%$.

The table below presents the OR and $95 \%$ CI for the presence of high CRP (>3.0 mg/l, level above the risk threshold) at adulthood according to change in weight status between adolescence and young adulthood. Odds of high CRP in adulthood were significantly higher in those who were overweight/obese at both time points and those who gained weight over time compared to those who remained normal weight.

\begin{tabular}{|c|c|c|c|c|c|}
\hline $\begin{array}{l}\text { BMI category at adolescence (age } 15) \& \text { at } \\
\text { young adulthood (mean age } 22.6 \mathrm{yrs})\end{array}$ & $\begin{array}{l}\mathrm{CRP}>3.0 \\
(\%)\end{array}$ & $\begin{array}{l}\text { Unadjusted OR } \\
(95 \% \mathrm{CI})\end{array}$ & $P$ & $\begin{array}{l}\text { Adjusted* OR } \\
(95 \% \mathrm{CI})\end{array}$ & $P$ \\
\hline Normal weight at both time points & 12.1 & Ref. Cat & & Ref. Cat & \\
\hline Change from overweight-obese to normal & 20 & $1.81(0.37,8.91)$ & 0.04 & $1.15(0.13,10.30)$ & 0.9 \\
\hline Change from normal to overweight-obese & 21.4 & $1.98(1.04,3.75)$ & 0.46 & $2.55(1.05,6.21)$ & 0.04 \\
\hline Overweight-obese at both time points & 27.7 & $2.77(1.33,5.80)$ & 0.01 & $2.81(1.02,7.79)$ & 0.05 \\
\hline
\end{tabular}

In conclusion, excess adiposity in adolescence may assist in predicting future CV risk status. Furthermore, remaining normal weight or losing weight over time may help promote favourable inflammatory states in later life. These results reinforce the need to prevent and address obesity early in life.

1. Brooks GC, Blaha MJ \& Blumenthal RS. (2010) Am J Cardiol 106, 56-61.

2. Cole TJ, Bellizzi MC, Flegal KM et al. (2000) Br Med J 320, 1240-1243.

3. World Health Organisation (1995) WHO Technical Report Series No. 854. Geneva: WHO.

4. Pearson A, Mensah GA, Alexander RW et al. (2003) Circulation 107, 499-511. 